\title{
Postmarketing surveillance of tocilizumab for rheumatoid arthritis in Japan: interim analysis of 3881 patients
}

\author{
Takao Koike, 1,2 Masayoshi Harigai, 2,3 Shigeko Inokuma, ${ }^{2,4}$ Naoki Ishiguro, 2,5 \\ Junnosuke Ryu, 2,6 Tsutomu Takeuchi, 2,7 Syuji Takei, ${ }^{2,8}$ Yoshiya Tanaka, 2,9 \\ Kyoko Ito, 2,10 Hisashi Yamanaka 2,11
}

\begin{abstract}
- Additional supplementary data are published online only. To view these files please visit the journal online at (http://ard.bmj.com)

${ }^{1}$ Hokkaido University Graduate School of Medicine, Hokkaido, Japan

2Postmarketing Surveillance Committee of the Japan College of Rheumatology, Tokyo, Japan ${ }^{3}$ Tokyo Medical and Dental University Graduate School, Tokyo, Japan

${ }^{4}$ Japanese Red Cross Medical Center, Tokyo, Japan

${ }^{5}$ Nagoya University Graduate School of Medicine, Aichi, Japan

${ }^{6}$ Nihon University School of Medicine, Tokyo, Japan ${ }^{7}$ Keio University, Tokyo, Japan ${ }^{8}$ Kagoshima University, Kagoshima, Japan ${ }^{9}$ University of Occupational and Environmental Health, Japan, Kitakyushu, Japan

${ }^{10}$ Chugai Pharmaceutical Co. Ltd., Tokyo, Japan

${ }^{11}$ Tokyo Women's Medical University, Tokyo, Japan
\end{abstract}

\section{Correspondence to}

Takao Koike, Department of Medicine II, Hokkaido University Graduate School of Medicine N-15 W-7, Kita-ku, Sapporo 060-8638, Japan; tkoike@med.hokudai.ac.jp

Accepted 17 July 2011 Published Online First 17 August 2011

\begin{abstract}
Objective An interim analysis of an all-patient postmarketing surveillance programme in Japan to investigate the safety of tocilizumab for the treatment of rheumatoid arthritis (RA) in the real world.

Methods This analysis included 3881 patients. Patients received $8 \mathrm{mg} / \mathrm{kg}$ of tocilizumab every 4 weeks, and were observed for 28 weeks. Data on baseline characteristics and adverse events (AE) were collected.

Results Total and serious AE were reported as 167 and 27 events/100 patient-years, respectively. The most frequent $A E$ and serious $A E$ were infections. Logistic regression analysis identified the following risk factors for the development of serious infection: concurrent or medical history of respiratory disorders; prednisolone dose at baseline $\geq 5 \mathrm{mg} /$ day; and age $\geq 65$ years. Twenty-five patients died, and the standardised mortality ratio, with the Japanese general population in 2008 as reference, was 1.66, similar to the results from the Japanese cohort study for RA patients.

Conclusions Tocilizumab is acceptably safe in the real clinical setting. Tocilizumab needs to be used with consideration of the benefit-risk balance to avoid serious infections in elderly patients and those on high doses of corticosteroids or with a concurrent or medical history of respiratory disorders.
\end{abstract}

Tocilizumab is a humanised anti-human interleukin 6 receptor monoclonal antibody. On the basis of previous clinical studies ${ }^{1-7}$ it was approved in Japan as an antirheumatic drug in 2008, and was subsequently approved in Europe in 2009 and in the USA in 2010.

The main objectives of all-patient postmarketing surveillance (PMS) programmes are to assess a drug's safety profile in the real world, to identify any risk factors for adverse events (AE) or adverse reactions, and also to verify effectiveness.

The PMS for tocilizumab was conducted from April 2008 to November 2009 as one of the conditions for approval in Japan, and a total of 8527 patients were enrolled. We report here the results of an interim safety analysis of 3881 registered patients who had completed 28 weeks of tocilizumab observation between April 2008 and July 2009.

\section{METHODS}

\section{Patients}

The PMS was conducted on all rheumatoid arthritis (RA) patients who received tocilizumab during the surveillance period in Japan. Tocilizumab was given to patients who showed inadequate response to at least one non-biological disease-modifying antirheumatic drug and who conformed to the Japan College of Rheumatology guidelines for tocilizumab ${ }^{8}$ (see supplementary text S1, available online only). Patients also had to be screened for tuberculosis based on an interview, a tuberculin skin test and a chest x-ray before initiation of tocilizumab treatment.

\section{Protocol}

Patient registration was controlled centrally (see supplementary text S2, available online only). Patients received an intravenous infusion of $8 \mathrm{mg} /$ $\mathrm{kg}$ of tocilizumab every 4 weeks. The observation period was from the initiation of tocilizumab treatment (week 0) to week 28. Data collected included baseline patient characteristics and all AE occurring during the 28 weeks or within 4 weeks of the last tocilizumab infusion.

\section{Statistical analysis}

AE were classified using system organ classes and preferred terms according to MedDRA v12.0. Univariate logistic analysis was used to screen for potential predictive variables, and a stepwise selection process was used for the multivariate regression model for identifying the risk factors for serious infections, interstitial lung disease (ILD), hepatic function abnormalities, cardiac disorders and death. The standardised mortality ratio was calculated relative to mortality in the general Japanese population in $2008 .{ }^{9} \mathrm{p}$ values below 0.05 were considered significant.

\section{RESULTS}

\section{Patient demographics}

In this interim report, 3881 RA patients were analysed (total exposure 1793.5 patient-years; mean observation period (SD) 24.1 (7.4) weeks) (see supplementary table S1 and supplementary text S3, available online only).

\section{Overall safety}

A total of $3004 \mathrm{AE}$ in 1641 patients (167.4/100 patient-years) and 490 serious adverse events (SAE) in 361 patients (27.3/100 patient-years) were reported. For $2330 \mathrm{AE}$ in 1379 patients (129.9/100 patient-years) and $363 \mathrm{SAE}$ in 278 patients (20.2/100 patient-years), it was judged 
that a causal relationship with tocilizumab could not be ruled out and these were classified as adverse drug reactions (ADR). The most common AE and SAE were infections and infestations (table 1).

\section{Clinically important AE}

The most common serious infection was pneumonia (47 events in 44 patients; $2.62 / 100$ patient-years). Five patients $(0.28 / 100$ patient-years) developed sepsis or septic shock (table 2).

Four patients developed tuberculosis ( $0.22 / 100$ patient-years). None of these patients had a history of tuberculosis. Two cases developed after more than 4 months of tocilizumab treatment, and the other two cases developed 24 days and 78 days after the beginning of tocilizumab infusion. All cases improved with appropriate treatment.

Twelve serious hepatobiliary disorders were reported in 11 patients (0.67/100 patient-years). No hepatitis B/C-positive patients or hepatitis $\mathrm{B} / \mathrm{C}$ virus carriers developed hepatobiliary disorders.

Twenty-five serious cardiac disorders were reported in 24 patients (1.39/100 patient-years). Of these patients, $13(54.2 \%)$ had a concurrent or medical history of cardiac disturbance.

Twenty-three ILD events were reported in 23 patients (1.28/100 patient-years); 13 patients had a concurrent or medical history of ILD, and an infection was a trigger for the onset of interstitial pneumonia in three patients.

Fifteen malignancies were reported in 15 patients $(0.84 / 100$ patient-years). At present, no specific patterns have been identified in terms of the types of malignancies.

Seven gastrointestinal perforations were reported in six patients (0.39/100 patient-years); in all cases, perforation occurred before the fifth dose of tocilizumab. All these patients had acute abdominal pain at onset and recovered with appropriate intervention including intestinal resections.

Death was reported in 25 patients (see supplementary table $\mathrm{S} 2$, available online only). The standardised mortality ratio was 1.66 (95\% CI 1.12 to 2.46$)$, which was similar to the results reported in the Japanese cohort study for RA. ${ }^{9}$

Significant risk factors identified for serious infections were age 65 years or greater, a concurrent or medical history of respiratory disease and corticosteroid dosage of $5 \mathrm{mg} /$ day or greater (prednisolone equivalent) at the baseline; risk factors for ILD were a concurrent or medical history of ILD and age 65 years or greater; risk factors for serious cardiac function disorders were a concurrent or medical history of cardiac function disorders and low bodyweight $(<40 \mathrm{~kg})$; risk factors for hepatic function disorders were a concurrent hepatic function disorder and the concomitant use of methotrexate; and risk

Table 1 The incidence rate (events/100 patient-years) of AE and ADR classified by SOC in RA patients treated with tocilizumab

\begin{tabular}{|c|c|c|c|c|c|c|c|c|}
\hline \multirow[b]{3}{*}{ SOC } & \multicolumn{2}{|c|}{ Total AE } & \multicolumn{2}{|c|}{ Serious AE } & \multicolumn{2}{|c|}{ Total ADR } & \multicolumn{2}{|c|}{ Serious ADR } \\
\hline & \multicolumn{2}{|c|}{ No of events } & \multicolumn{2}{|c|}{ No of events } & \multicolumn{2}{|c|}{ No of events } & \multicolumn{2}{|c|}{ No of events } \\
\hline & \multicolumn{2}{|c|}{ (/100 patient-years) } & \multicolumn{2}{|c|}{ (/100 patient-years) } & \multicolumn{2}{|c|}{ (/100 patient-years) } & \multicolumn{2}{|c|}{ /100 patient-years } \\
\hline Total & 3,004 & (167.49) & 490 & (27.32) & 2,330 & $(129.91)$ & 363 & (20.24) \\
\hline Infections and infestations & 553 & $(30.83)$ & 163 & (9.09) & 447 & $(24.92)$ & 147 & (8.20) \\
\hline Laboratory test abnormalities & 636 & $(35.46)$ & 39 & $(2.17)$ & 563 & (31.39) & 36 & (2.01) \\
\hline Hepatobiliary disorders & 269 & $(15.00)$ & 12 & $(0.67)$ & 213 & $(11.88)$ & 11 & $(0.61)$ \\
\hline $\begin{array}{l}\text { Skin and subcutaneous tissue } \\
\text { disorders }\end{array}$ & 247 & $(13.77)$ & 6 & $(0.33)$ & 205 & (11.43) & 6 & $(0.33)$ \\
\hline Gastrointestinal disorders & 221 & $(12.32)$ & 42 & (2.34) & 145 & (8.08) & 30 & $(1.67)$ \\
\hline $\begin{array}{l}\text { Respiratory, thoracic and } \\
\text { mediastinal disorders }\end{array}$ & 207 & $(11.54)$ & 37 & $(2.06)$ & 150 & (8.36) & 26 & $(1.45)$ \\
\hline $\begin{array}{l}\text { Metabolism and nutrition } \\
\text { disorders }\end{array}$ & 172 & (9.59) & 4 & $(0.22)$ & 159 & (8.87) & 3 & $(0.17)$ \\
\hline $\begin{array}{l}\text { General disorders and } \\
\text { administration site conditions }\end{array}$ & 145 & (8.08) & 18 & $(1.00)$ & 124 & (6.91) & 16 & $(0.89)$ \\
\hline $\begin{array}{l}\text { Musculoskeletal and connective } \\
\text { tissue disorders }\end{array}$ & 135 & $(7.53)$ & 20 & $(1.12)$ & 87 & $(4.85)$ & 12 & $(0.67)$ \\
\hline Nervous system disorders & 102 & (5.69) & 21 & $(1.17)$ & 70 & (3.90) & 13 & $(0.72)$ \\
\hline $\begin{array}{l}\text { Blood and lymphatic system } \\
\text { disorders }\end{array}$ & 64 & $(3.57)$ & 23 & $(1.28)$ & 51 & (2.84) & 19 & $(1.06)$ \\
\hline Vascular disorders & 63 & (3.51) & 13 & $(0.72)$ & 33 & $(1.84)$ & 7 & $(0.39)$ \\
\hline $\begin{array}{l}\text { Injury, poisoning and procedural } \\
\text { complications }\end{array}$ & 53 & $(2.96)$ & 34 & $(1.90)$ & 5 & $(0.28)$ & 3 & $(0.17)$ \\
\hline Cardiac disorders & 45 & $(2.51)$ & 25 & $(1.39)$ & 33 & $(1.84)$ & 17 & $(0.95)$ \\
\hline Renal and urinary disorders & 21 & $(1.17)$ & 5 & $(0.28)$ & 12 & $(0.67)$ & 3 & $(0.17)$ \\
\hline Eye disorders & 20 & $(1.12)$ & 1 & $(0.06)$ & 10 & $(0.56)$ & 1 & $(0.06)$ \\
\hline $\begin{array}{l}\text { Neoplasms benign, malignant } \\
\text { and unspecified (including cysts } \\
\text { and polyps) }\end{array}$ & 18 & $(1.00)$ & 15 & $(0.84)$ & 7 & $(0.39)$ & 5 & $(0.28)$ \\
\hline Psychiatric disorders & 11 & $(0.61)$ & 2 & $(0.11)$ & 2 & $(0.11)$ & 0 & $(0.00)$ \\
\hline Immune system disorders & 8 & $(0.45)$ & 7 & (0.39) & 8 & $(0.45)$ & 7 & (0.39) \\
\hline Ear and labyrinth disorders & 6 & $(0.33)$ & 2 & $(0.11)$ & 3 & $(0.17)$ & 1 & $(0.06)$ \\
\hline Endocrine disorders & 4 & $(0.22)$ & 1 & $(0.06)$ & 1 & $(0.06)$ & 0 & $(0.00)$ \\
\hline $\begin{array}{l}\text { Reproductive system and breast } \\
\text { disorders }\end{array}$ & 4 & $(0.22)$ & 0 & $(0.00)$ & 2 & $(0.11)$ & 0 & $(0.00)$ \\
\hline
\end{tabular}

ADR, adverse drug reaction; $A E$, adverse event; RA, rheumatoid arthritis; SOC, Medical Dictionary for Regulatory Activities (MedDRA) system organ class (MedDRA v12.0). 
Table 2 Common SAE in tocilizumab-treated RA patients

\begin{tabular}{|c|c|c|}
\hline \multirow[b]{3}{*}{ Total } & \multicolumn{2}{|c|}{ No of events } \\
\hline & \multicolumn{2}{|c|}{ (/100 patient-years) } \\
\hline & 490 & $(27.3)$ \\
\hline Infections and infestations & 163 & (9.09) \\
\hline Pneumonia* & 47 & $(2.62)$ \\
\hline Cellulitis & 19 & $(1.06)$ \\
\hline Herpes zoster & 11 & $(0.61)$ \\
\hline Atypical mycobacterial infection & 9 & $(0.50)$ \\
\hline Arthritis bacterial and arthritis infective & 9 & $(0.50)$ \\
\hline Diverticulitis & 6 & $(0.33)$ \\
\hline Pneumocystis jiroveci pneumonia & 5 & $(0.28)$ \\
\hline Sepsis and septic shock & 5 & $(0.28)$ \\
\hline Gastroenteritis & 5 & $(0.28)$ \\
\hline Tuberculosis $^{\dagger}$ & 4 & $(0.22)$ \\
\hline Bronchitis & 4 & $(0.22)$ \\
\hline Pyelonephritis & 4 & $(0.22)$ \\
\hline Malignancies & 15 & $(0.84)$ \\
\hline Breast cancer & 2 & $(0.11)$ \\
\hline Gastric cancer & 2 & $(0.11)$ \\
\hline B-cell lymphoma & 1 & $(0.06)$ \\
\hline Basal cell carcinoma & 1 & $(0.06)$ \\
\hline Bile duct cancer & 1 & $(0.06)$ \\
\hline Bladder neoplasm & 1 & $(0.06)$ \\
\hline Lymphoma & 1 & $(0.06)$ \\
\hline Meningioma & 1 & $(0.06)$ \\
\hline Pleural mesothelioma & 1 & $(0.06)$ \\
\hline Uterine cancer & 1 & $(0.06)$ \\
\hline Large intestine carcinoma & 1 & $(0.06)$ \\
\hline Cervix carcinoma & 1 & $(0.06)$ \\
\hline Lung neoplasm & 1 & $(0.06)$ \\
\hline \multicolumn{3}{|l|}{ Others } \\
\hline Cardiac function disorder & 25 & $(1.39)$ \\
\hline ILD and organising pneumonia & 23 & $(1.28)$ \\
\hline White blood cell count decreased & 15 & $(0.84)$ \\
\hline Hepatobiliary disorder & 12 & $(0.67)$ \\
\hline Neutrophil count decreased & 10 & $(0.56)$ \\
\hline $\begin{array}{l}\text { Anaphylactic reaction, anaphylactic shock, } \\
\text { anaphylactoid reaction and hypersensitivity }\end{array}$ & 7 & $(0.39)$ \\
\hline Fever & 7 & $(0.39)$ \\
\hline Gastrointestinal perforation ${ }^{\ddagger}$ & 7 & $(0.39)$ \\
\hline Melaena & 7 & (0.39) \\
\hline Neutropenia & 6 & $(0.33)$ \\
\hline Acute myocardial infarction & 6 & $(0.33)$ \\
\hline RA & 6 & $(0.33)$ \\
\hline Vertebral compression fracture & 6 & $(0.33)$ \\
\hline Cerebral infarction & 5 & $(0.28)$ \\
\hline Pneumothorax & 5 & $(0.28)$ \\
\hline Leucopenia & 5 & $(0.28)$ \\
\hline Disseminated intravascular coagulation & 4 & $(0.22)$ \\
\hline Arthralgia & 4 & $(0.22)$ \\
\hline \multicolumn{3}{|c|}{$\begin{array}{l}\text { *Pneumonia: includes bronchial pneumonia, lobar pneumonia, pneumonia, mycoplasmal } \\
\text { pneumonia, primary atypical pneumonia, bacterial pneumonia and pneumococcal } \\
\text { pneumonia. } \\
\text { 'Tuberculosis: pulmonary tuberculosis in three of the patients and peritoneal } \\
\text { tuberculosis in one. } \\
{ }^{\ddagger} \text { Gastrointestinal perforations: includes appendicitis perforated, gastric perforation, } \\
\text { intestinal perforation, large intestinal perforation, and small intestinal perforation. } \\
\text { ILD, interstitial lung disease; RA, rheumatoid arthritis; SAE, serious adverse event. }\end{array}$} \\
\hline
\end{tabular}

factors for death were age 65 years or greater, a concurrent or medical history of cardiac disorders, concurrent renal impairment and Steinbrocker class 3 or 4 (table 3 and supplementary text $\mathrm{S} 4$, available online only). Although serum total cholesterol was increased to greater than $300 \mathrm{mg} / \mathrm{dl}$ in 100 patients $(2.6 \%)$ and triglycerides were increased to greater than 375 $\mathrm{mg} / \mathrm{dl}$ in 70 patients $(1.8 \%)$, no patients who showed these abnormalites continuously developed serious cardiac function disorders.

\section{DISCUSSION}

In this interim analysis, the safety profile of tocilizumab in Japanese RA patients in the real world was clarified.

The most common AE and SAE reported in this analysis were infections and infestations. The incidence rate of infections as SAE was higher in this report (9.1/100 patient-years) than in the tocilizumab clinical study in Japan $(6.2 / 100 \text { patient-years })^{10}$ or in other tocilizumab global clinical studies. ${ }^{1-7}$ In this PMS, all patients were enrolled including those who had risk factors for serious infections, and all $\mathrm{AE}$ were monitored after initiating treatment. In the clinical trials, on the other hand, although the incidence rate of reported $\mathrm{AE}$ is accurate because all $\mathrm{AE}$ are recorded, patients were excluded for a number of conditions including risk factors for serious infection. These factors might make a difference between this PMS and clinical studies in the incidence rates of serious infections.

Although there was no parallel control study and patient background might be not comparable, in terms of infections as serious ADR our results (8.20/100 patient-years; $3.4 \%)$ were equivalent to the results of 6 months' infliximab PMS data (8.56/100 patientyears) ${ }^{11}$ and higher than 6 months' etanercept PMS data $(2.4 \%)$ (PMS report www.enbrel.jp/member/report/kansetsu_7.html). These results suggest that, in common with other anti-tumour necrosis factor (TNF) biological agents, careful monitoring of signs and symptoms of infection is important during treatment with tocilizumab to avoid the development of serious infections, especially in patients with identified risk factors. ${ }^{11} 12$

The reactivation of tuberculosis is a major concern during anti-TNF treatment, but there is no medical consensus regarding the effect of interleukin 6 signal inhibition on tuberculosis. ${ }^{13} 14$ Therefore, all patients were screened for tuberculosis in the same way as those receiving anti-TNF treatments, and chemoprophylaxis was provided as needed before starting tocilizumab treatment. As a result, the incidence rate of tuberculosis in this study $(0.1 \%, 0.22 / 100$ patient-years) was equivalent to that in the PMS of infliximab (0.3\%) and etanercept $(0.1 \%) .{ }^{11} 12$ Because tuberculosis developed in various periods after the initiation of tocilizumab treatment, the collection of case reports and further detailed study will be needed to clarify the risk factors for tuberculosis developing during tocilizumab treatment.

ILD was reported more frequently in this PMS study than in the clinical studies, ${ }^{10}$ but the incidence rate of this AE was equivalent to that found in the PMS of infliximab and etanercept in Japan. ${ }^{11,12}$ As infection is a trigger for the onset of interstitial pneumonia, careful monitoring of infection will be mandatory in patients with a concurrent or medical history of ILD.

Serious hepatic function disorders through the reactivation of hepatitis virus were not reported in this study. Nevertheless, tocilizumab treatment of patients infected with hepatitis virus (ie, hepatitis virus carriers or patients with viral hepatitis) is not recommended at present because there is limited experience with tocilizumab treatment in these patients, and because the reactivation of hepatitis $B$ was reported during anti-TNF therapy. ${ }^{15}$ Moreover, because the concomitant use of methotrexate was shown to be a risk factor for hepatic function disorders, hepatic function should be periodically tested when tocilizumab is used with methotrexate.

As a concurrent or medical history of cardiovascular disorders and low bodyweight are risk factors for developing cardiovascular disease, careful monitoring is needed in these patients.

Anaphylaxis was reported in seven patients $(0.4 / 100$ patientyears). All of these cases were reported before the fourth infusion of tocilizumab. Therefore, careful monitoring for anaphylaxis is required in the early phase of tocilizumab treatment. 
Table 3 Risk factors for AE (results based on multiple logistic regression analysis)

\begin{tabular}{|c|c|c|c|c|c|c|}
\hline Event & Factor & Prevalence* $(\%)$ & & $\mathbf{O R}$ & $95 \% \mathrm{Cl}$ & p Value \\
\hline \multirow{5}{*}{$\begin{array}{l}\text { Serious infections and } \\
\text { infestations }\end{array}$} & Age, years $(\geq 65 \text { vs }<65)^{\dagger}$ & $75 / 1406(5.33)$ & $70 / 2473(2.83)$ & 1.699 & 1.152 to 2.505 & 0.0075 \\
\hline & Respiratory disease (concurrent or medical history) (yes vs no) & $68 / 841(8.09)$ & $77 / 3040(2.53)$ & 3.428 & 2.308 to 5.092 & $<0.0001$ \\
\hline & $\begin{array}{l}\text { Oral corticosteroids (mg/day, prednisolone-equivalent) (at } \\
\text { baseline) }\end{array}$ & & & & & \\
\hline & (<5 mg/day vs 0 mg/day) & $58 / 1845(3.14)$ & $25 / 1032(2.42)$ & 1.114 & 0.647 to 1.915 & 0.6973 \\
\hline & ( $\geq 5 \mathrm{mg} /$ day vs $0 \mathrm{mg} /$ day) & $62 / 1004(6.18)$ & $25 / 1032(2.42)$ & 2.165 & 1.254 to 3.738 & 0.0056 \\
\hline \multirow[t]{2}{*}{ ILD $^{\ddagger}$} & Age, years $(\geq 65 \text { vs }<65)^{\dagger}$ & $16 / 1406(1.14)$ & $7 / 2473(0.28)$ & 4.304 & 1.532 to 12.091 & 0.0056 \\
\hline & ILD (concurrent or medical history) (yes vs no)no & $13 / 428(3.04)$ & $10 / 3453(0.29)$ & 7.950 & 3.129 to 20.200 & $<0.0001$ \\
\hline \multirow{2}{*}{$\begin{array}{l}\text { Hepatic function } \\
\text { disorders }^{\S}\end{array}$} & Methotrexate (concomitant drug) (yes vs no) & $214 / 1942(11.02)$ & $106 / 1939(5.47)$ & 2.174 & 1.705 to 2.771 & $<0.0001$ \\
\hline & Hepatic function disorders (concurrent) (yes vs no) & $30 / 176(17.05)$ & $290 / 3705(7.83)$ & 2.546 & 1.681 to 3.857 & $<0.0001$ \\
\hline \multirow[t]{2}{*}{$\begin{array}{l}\text { Cardiac function } \\
\text { disorders }\end{array}$} & $\begin{array}{l}\text { Cardiac function disorders (concurrent or medical history) (yes } \\
\text { vs no) }\end{array}$ & $13 / 250(5.20)$ & $11 / 3631(0.30)$ & 15.618 & 6.054 to 40.294 & $<0.0001$ \\
\hline & Bodyweight $(>40 \mathrm{~kg} \mathrm{vs} \leq 40 \mathrm{~kg})^{\dagger}$ & $16 / 3232(0.50)$ & $6 / 234(2.56)$ & 0.235 & 0.077 to 0.717 & 0.0416 \\
\hline \multirow[t]{4}{*}{ Death } & Age, years $(\geq 65 \text { vs }<65)^{\dagger}$ & $20 / 1406(1.42)$ & $5 / 2473(0.20)$ & 3.274 & 1.161 to 9.232 & 0.0249 \\
\hline & Steinbrocker class $(3+4$ vs $1+2)$ & $17 / 1037(1.64)$ & $8 / 2831(0.28)$ & 3.505 & 1.361 to 9.027 & 0.0094 \\
\hline & Cardiac disorders (concurrent or medical history) (yes vs no) & $8 / 250(3.20)$ & $17 / 3631(0.47)$ & 3.607 & 1.422 to 9.146 & 0.0069 \\
\hline & Renal impairment (concurrent) (yes vs no) & $9 / 187(4.81)$ & $16 / 3694(0.43)$ & 3.876 & 1.354 to 11.098 & 0.0116 \\
\hline
\end{tabular}

\begin{abstract}
*Prevalence is described as (number of patients who developed adverse events; AE)/(numb
'Data were not collected in two cases.
‡ILD (interstitial lung disease) includes interstitial pneumonia and organising pneumonia.

In conclusion, these results show that tocilizumab was well tolerated and the safety of tocilizumab is within an acceptable range in the real clinical setting. Because this surveillance was conducted only 28 weeks, a long-term surveillance programme is also currently underway to clarify the long-term safety of tocilizumab in daily clinical practice in Japan.
\end{abstract}

§Hepatic function disorders include liver function test abnormalities (increased levels of aspartate aminotransferase, alanine aminotransferase, or $\gamma$-glutamyl transpeptidase). Acknowledgements The authors wish to thank all investigators for their
contributions to the implementation of this study.

Funding This study was funded by Chugai Pharmaceutical Co, Ltd. Data were collected and analysed by Chugai according to the prespecified protocol. Medical writing and editorial assistance were also provided by Chugai following a face-to-face meeting with all authors during which the data, its interpretation and the content of the paper were discussed.

Competing interests $\mathrm{TK}, \mathrm{MH}, \mathrm{SI}, \mathrm{NI}, \mathrm{JR}, \mathrm{TT}, \mathrm{ST}, \mathrm{YT}$ and $\mathrm{HY}$ are all members of the Postmarketing Surveillance Committee of the Japan College of Rheumatology. The Committee was created in response to a request for assistance from the Ministry of Health, Labour and Welfare (MLHW) of Japan. The role of the committee is to provide independent advice to Chugai Pharmaceutical Co Ltd on conducting the PMS programme mandated by the MHLW and on the results thereof. Participation on this committee is not compensated for. It is the belief of the first author that this position does not constitute a conflict of interest. The doctors participated in the review and analysis of the PMS data in their capacity as committee members and are so listed. TK, MH, NI, JR, TT and YT have received research grants, consultant fees, and/or speakers' bureau honoraria from Chugai Pharmaceutical Co Ltd. HY is a member of the advisory board and has received research grants, consultant fees and speakers' bureau honoraria from Chugai Pharmaceutical Co Ltd and Roche. KI is a full-time employee of Chugai Pharmaceutical Co Ltd.

\section{Patient consent Obtained.}

Ethics approval This postmarketing surveillance was initiated after the synopsis was submitted to MHLW in advance. Approval has been obtained from each ethics committee in the hospitals that participated in the surveillance.

Provenance and peer review Not commissioned; externally peer reviewed.

\section{REFERENCES}

1. Nishimoto N, Miyasaka N, Yamamoto K, et al. Study of active controlled tocilizumab monotherapy for rheumatoid arthritis patients with an inadequate response to methotrexate (SATORI): significant reduction in disease activity and serum vascular endothelial growth factor by IL-6 receptor inhibition therapy. Mod Rheumatol 2009;19:12-19.

2. Nishimoto N, Hashimoto J, Miyasaka N, et al. Study of active controlled monotherapy used for rheumatoid arthritis, an IL-6 inhibitor (SAMURAI): evidence of clinical and radiographic benefit from an $\mathrm{x}$ ray reader-blinded randomised controlled trial of tocilizumab. Ann Rheum Dis 2007:66:1162-7.

3. Nishimoto N, Miyasaka N, Yamamoto K, et al. Long-term safety and efficacy of tocilizumab, an anti-IL-6 receptor monoclonal antibody, in monotherapy, in patients with rheumatoid arthritis (the STREAM study): evidence of safety and efficacy in a 5-year extension study. Ann Rheum Dis 2009;68:1580-4.

4. Smolen JS, Beaulieu A, Rubbert-Roth A, et al. Effect of interleukin-6 receptor inhibition with tocilizumab in patients with rheumatoid arthritis (OPTION study): a double-blind, placebo-controlled, randomised trial. Lancet 2008;371:987-97.

5. Genovese MC, McKay JD, Nasonov EL, et al. Interleukin-6 receptor inhibition with tocilizumab reduces disease activity in rheumatoid arthritis with inadequate response to disease-modifying antirheumatic drugs: the tocilizumab in combination with traditional disease-modifying antirheumatic drug therapy study. Arthritis Rheum 2008;58:2968-80.

6. Jones G, Sebba A, Gu J, et al. Comparison of tocilizumab monotherapy versus methotrexate monotherapy in patients with moderate to severe rheumatoid arthritis: the AMBITION study. Ann Rheum Dis 2010;69:88-96.

7. Emery $\mathbf{P}$, Keystone $\mathrm{E}$, Tony HP, et al. IL-6 receptor inhibition with tocilizumab improves treatment outcomes in patients with rheumatoid arthritis refractory to anti-tumour necrosis factor biologicals: results from a 24-week multicentre randomised placebocontrolled trial. Ann Rheum Dis 2008;67:1516-23.

8. Koike R, Harigai M, Atsumi T, et al. Japan College of Rheumatology 2009 guidelines for the use of tocilizumab, a humanized anti-interleukin-6 receptor monoclonal antibody, in rheumatoid arthritis. Mod Rheumato/ 2009;19:351-7.

9. Nakajima A, Inoue E, Tanaka E, et al. Mortality and cause of death in Japanese patients with rheumatoid arthritis based on a large observational cohort, IORRA. Scand J Rheumatol 2010;39:360-7.

10. Nishimoto N, Ito K, Takagi N. Safety and efficacy profiles of tocilizumab monotherapy in Japanese patients with rheumatoid arthritis: meta-analysis of six initial trials and five long-term extensions. Mod Rheumatol 2010;20:222-32.

11. Takeuchi T, Tatsuki Y, Nogami Y, et al. Postmarketing surveillance of the safety profile of infliximab in 5000 Japanese patients with rheumatoid arthritis. Ann Rheum Dis 2008;67:189-94.

12. Koike T, Harigai M, Inokuma S, et al. Postmarketing surveillance of safety and effectiveness of etanercept in Japanese patients with rheumatoid arthritis. Mod Rheumatol 2011; Published online first :25 January 2011.

13. Welsh KJ, Abbott AN, Hwang SA, et al. A role for tumour necrosis factoralpha, complement $\mathrm{C} 5$ and interleukin- 6 in the initiation and development of the mycobacterial cord factor trehalose 6,6'-dimycolate induced granulomatous response. Microbiology (Reading, Engl) 2008;154:1813-24.

14. Saunders BM, Frank AA, Orme IM, et al. Interleukin-6 induces early gamma interferon production in the infected lung but is not required for generation of specific immunity to Mycobacterium tuberculosis infection. Infect Immun 2000;68:3322-6.

15. Carroll MB, Forgione MA. Use of tumor necrosis factor alpha inhibitors in hepatitis B surface antigen-positive patients: a literature review and potential mechanisms of action. Clin Rheumatol 2010;29:1021-9. 